\title{
NOTA
}

\section{ASPECTOS LEGAIS DA DEGRADAÇÃO DE SOLOS EM ÁREAS DE PRESERVAÇÃO PERMANENTE EM MINERAÇÃO DE AREIA NO MÉDIO IGUAÇU ${ }^{(1)}$}

\author{
Katia Aparecida Juliano ${ }^{(2)}$, Donizeti Antônio Giusti ${ }^{(3)}$ \& \\ Ana Maria Muratori ${ }^{(4)}$
}

\begin{abstract}
RESUMO
No presente trabalho foram analisados aspectos legais concernentes à invasão de áreas de preservação permanente pela mineração de areia. Escolheu-se como estudo de caso a mineração de areia no médio Iguaçu, especificamente na região do município de União da Vitória, Estado do Paraná, onde há concentração de empresas mineradoras que foram objeto de procedimentos investigatórios do Ministério Público Estadual. A invasão de APPs (áreas de preservação permanente) ocorre em todos os areais instalados na região, sob todas as formas de exploração, ou seja, nas explorações do leito do rio, nas planícies de aluvião e nas encostas de morro. Esse problema é tratado como de menor importância em todos os trabalhos técnicos, relatórios e planos de recuperação ambiental das áreas degradadas apresentados ao órgão ambiental estadual, sendo desconsiderado, em todos eles, que a invasão de APP é crime ambiental. Os Procedimentos Investigatórios do Ministério Público do Estado do Paraná foram pesquisados pelos autores, principalmente em seus aspectos técnicos relativos à degradação e recuperação dos solos, com o objetivo de discutir soluções para o problema.
\end{abstract}

Termos de indexação: crime ambiental, areais, áreas de preservação permanente, degração do solo.

\footnotetext{
(1) Parte da Tese de Mestrado em Ciências dos Solos do Programa de Pós-Graduação em Agronomia: Ciência do Solo da Universidade Federal do Paraná - UFPR. Recebido para publicação em dezembro de 2005 e aprovado em agosto de 2007.

(2) Perita Criminal do Instituto de Criminalística do Estado do Paraná. Av. Visconde de Guarapuava 2652, CEP 80010-100 Curitiba (PR). E-mail: kjuliano@pop.com.br

${ }^{(3)}$ Professor Adjunto do Departamento de Geologia da Universidade Federal do Paraná - UFPR. Praça Santos Andrade 50, CEP 81531-900 Curitiba (PR). E-mail: donizeti@ufpr.br

(4) Professora Adjunta do Departamento de Geografia, UFPR. Centro Politécnico, Caixa Postal 19001, Jardim das Américas, CEP 81531-990 Curitiba (PR). E-mail: amuratori@uol.com.br
} 


\title{
SUMMARY: LEGAL ASPECTS OF DESTRUCTION IN PERMANENT PRESERVATIONAREAS (APP) BY SAND MINING EXPLORATION IN THE MIDDLE IGUAÇU RIVER
}

\begin{abstract}
This study analyzed legal aspects concerning the invasion of permanent preservation areas by sand mining. A sand mine in the middle Iguaçu river, more exactly in the region of the county of União da Vitória, state of Paraná, was chosen as study case. In this region there is a concentration of mining companies that had been under investigation on behalf of the Ministry for Environment. The invasion of APPs (permanent preservation areas) occurs in all "areais" (sand depositions) in the region, using all forms of exploitation, in other words, mining in the river bed, alluvial plains and hill slopes. In all technical studies, reports and plans of environmental recovery of the degraded areas presented before the Ministry for Environment, the problem is understated. The fact that the invasion of an $A P P$ is an environmental crime is not taken into consideration by any of them. The Proceedings of investigation of the Ministry for Environment of the state of Parana were scrutinized by the authors, mainly in the technical aspects related to soil degradation and recovery, with the objective of discussing solutions to the problem.
\end{abstract}

Index terms: environmental crime, sand depositions, permanent preservation areas, soil degradation.

\section{INTRODUÇÃO}

Os profissionais das áreas técnicas que elaboraram os planos de exploração e recuperação de áreas degradadas nos areais pesquisadas têm definido área de preservação permanente (APP) correspondente a uma faixa de $30 \mathrm{~m}$ das margens do rio Iguaçu (Juliano, 2005). Esta definição baseia-se na interpretação equivocada do parágrafo único do artigo $2^{\circ}$ do Código Florestal, que diz o seguinte:

Parágrafo único - No caso de áreas urbanas, assim entendidas as compreendidas nos perímetros urbanos definidos por lei municipal e nas regiões metropolitanas e aglomerações urbanas, em todo o território abrangido, observar-se-á o disposto nos respectivos planos diretores e leis de uso do solo, respeitados os princípios e limites a que se refere este artigo. (Parágrafo acrescentado pela Lei $n^{\circ} 7.803$ de 18.7.1989) (Brasil, 1989).

O erro tem origem na interpretação deste parágrafo, pois em todos os areais os profissionais definem a faixa de APP de acordo com a legislação de uso e ocupação dos solos. Note-se, porém, que o artigo é claro: "observar-se-á o disposto nos respectivos planos diretores e leis de uso do solo, respeitados os princípios e limites a que se refere este artigo". No caso, os limites a serem observados são os citados expressamente no artigo $2^{\circ}$ do Código Florestal. O Código Florestal foi instituído pela Lei 4.771 (Brasil, 2004), que é uma lei federal; assim, os limites desta lei têm de ser observados antes da aplicação de qualquer norma estadual ou municipal referente ao assunto. A aplicação de uma lei estadual, norma ou mesmo resolução, não se sobrepõe à da lei federal.
A questão legal da invasão de áreas de preservação permanente pela atividade de extração de areia é um problema sério que terá de ser resolvido, pois trata-se de um crime ambiental. Neste trabalho, além de uma discussão sobre o tema, são feitas propostas técnicas para melhor avaliação dos impactos ambientais dessa atividade, no sentido de discutir soluções para o problema no médio Iguaçu.

\section{MATERIAL E MÉTODOS}

Para este trabalho, foram analisados o EIA-RIMA (2003) realizado na região do médio Iguaçu, entre os municípios de São Mateus do Sul e Porto Vitória, no Estado do Paraná, que foi exigência do Ministério Público aos mineradores da região, o qual faz parte de um TAC (Termo de Ajuste de Conduta) assinado em fevereiro de 2003 pelos mineradores e o Ministério Público do Estado do Paraná; o Processo Investigatório Preliminar $n^{\circ} 259 / 2002$, instaurado pela $1^{a}$ Promotoria de Justiça de Defesa do Meio Ambiente de União da Vitória, PR, que investiga a atividade de extração irregular de areia na região de União da Vitória, com danos ao meio ambiente; os Planos de Recuperação Ambiental e Planos de Lavra de todos os areais instalados entre os municípios de União da Vitória e Porto Vitória, na região do médio Iguaçu, PR; a Ação Civil Pública de Responsabilidade por Danos Causados ao Meio Ambiente $\mathrm{n}^{\circ} 555 / 1989$; e o Plano de Recuperação Ambiental da Curva da Ressaca (1997).

Todos esses documentos foram consultados em razão de um dos autores ser perito criminal no Estado do Paraná; eles se encontram em poder do Ministério Público do Paraná. 


\section{RESULTADOS E DISCUSSÃO}

Pela análise dos documentos, nota-se que há descaso generalizado quanto à invasão de APPs (áreas de preservação permanente). Na análise dos impactos, o EIA-RIMA não aborda a invasão de APPs pela mineração de areia em encostas de morro - estas também referidas na legislação ambiental como APPs - e torna sem importância o problema no tocante à instalação de portos de areia e explorações em cavas, ao afirmar que: "As atuais atividades minerárias, incluindo-se a exploração em cavas e a instalação de portos de areia, ocupam cerca de 50 ha, o que representa 1,15 \% das APPs deste trecho do rio" (EIARIMA 2003). Todavia, números constatados na análise das jazidas são bastante diversos. Uma única jazida explorada na planície de inundação do rio Iguaçu ocupa uma área de 181,2 ha, praticamente toda ela dentro de área de preservação permanente (Juliano, 2005). Convém referir que a área delimitada como APP no EIA-RIMA compreende uma faixa de $100 \mathrm{~m}$ de cada lado das margens do rio e adota uma extensão de 216,5 km lineares no trecho entre São Mateus e Porto Vitória, o que resulta em 4.330 ha de área total de preservação permanente. Como se chegou a um total de apenas 50 ha de APPs invadidas, 1,15\% do total é incompreensível quando se analisa a área das jazidas.

A tentativa de mascarar o problema com números que não se sustentam diante de uma rápida análise dos dados e o uso de legislação mais conveniente não surtem os efeitos legais desejados. O EIA-RIMA(2003), da forma como foi realizado, teve pareceres desfavoráveis emitidos por vários órgãos e não foi aceito pelo Ministério Público Estadual, o que implicará mais custos e conflitos legais para atividade de mineração na região.

Das análises dos trabalhos técnicos apresentados ao Ministério Público e de trabalhos acadêmicos referentes à mineração, todos realizados por engenheiros e geólogos, depreende-se que há entendimento equivocado no que se refere também ao artigo 225 da Constituição Federal de 1988, que, segundo alguns trabalhos, daria "permissão de degradar, ao reconhecer no $\S 2^{\circ}$ que a atividade mineradora fatalmente degrada o meio ambiente", nos seguintes termos:

Art 225. $\S 22^{\circ}$ Aquele que explorar recursos minerais fica obrigado a recuperar o meio ambiente degradado, de acordo com solução técnica exigida pelo órgão público competente, na forma da lei.

Afirmações dessa natureza induzem a uma certa indulgência por parte dos profissionais que atuam na atividade mineradora quanto à infração das leis ambientais. É certo que a legislação pertinente reconhece que a mineração degrada o meio ambiente quando tacitamente obriga a recuperação das áreas mineradas para que haja uso futuro do solo. Contudo, o reconhecimento de que a exploração mineral sempre degrada o meio ambiente não é permissão nem atenuante para condutas ambientais que hoje são consideradas crime.

No decorrer da pesquisa bibliográfica e análise de documentos técnicos, encontraram-se afirmações quanto a "importância da mineração de areia nas várzeas do Iguaçu no combate às enchentes". A seguir são transcritos alguns trechos característicos:

\begin{abstract}
"Hoje admite-se que as minerações que extraem areia nas várzeas dos rios Iguaçu e seus afluentes são coadjuvantes importantes na estratégia de combate a enchentes e no combate ao estabelecimento de invasões e loteamentos ilegais nas várzeas e fundos de vale. (Perfil do mercado Produtor de Areia no Paraná, Mineropar, 2001)."
\end{abstract}

"Os empreendimentos que extraem areia nas várzeas do rio Iguaçu e seus afluentes têm importante contribuição no combate às enchentes e evitam invasões e loteamentos ilegais em áreas inadequadas como as Várzeas e fundos de vale"(Areia \& Brita, 1998).

"A mineração de areia na RMC (Região Metropolitana de Curitiba) é uma atividade combatida pela população de um modo geral pelo fato de provocar danos ao meio ambiente. Contudo, na RMC, tal atividade vem se tornando coadjuvante importante na estratégia de controle às enchentes e no combate ao estabelecimento de invasões e loteamentos ilegais nas áreas de várzeas e fundo de vale do alto curso do Iguaçu e seus afluentes." (Magalhães, 2002).

Pelos termos usados pelos autores, percebe-se que é a reprodução de uma afirmação que ganhou importância e status de conclusão científica dada a própria repetição. No entanto, é elementar a afirmação de que alterar as características do leito de um rio em um dado trecho e sua várzea implica conseqüências que devem ser estudadas caso a caso. O problema das cheias em um determinado lugar é complexo, sendo o resultado de vários fatores particulares.

Quanto ao combate às invasões, estudos na Região Metropolitana de Curitiba (RMC), em locais de solos degradados pela mineração e abandonados sem nenhum processo de reabilitação, mostram que a conclusão a respeito da importância da mineração como coadjuvante no combate ao estabelecimento de invasões e loteamentos clandestinos é completamente equivocada. Segundo Fabianovicz (1998), que estudou o conflito entre a extração de areia e a ocupação urbana na região da Grande Curitiba, há na RMC grande 
número de áreas que foram mineradas e que não passaram por processo algum de reabilitação; algumas cavas abandonadas tornaram-se depósitos clandestinos de lixo e, em alguns casos, favoreceram as invasões, além de comprometerem as condições sanitárias e de saúde da população.

Percebe-se que conclusões que já são equivocadas para a RMC estão sendo generalizadas para todo o rio Iguaçu no tocante à exploração de areia. Cada região apresenta problemas específicos, e as soluções só surgirão da análise de informações realmente significativas.

É importante lembrar que a atividade minerária instalou-se na região do médio Iguaçu há muito tempo; alguns portos de areia datam de 50 anos atrás. Evidentemente que a legislação na época não contemplava questões ambientais, e, mesmo com a instituição do Código Florestal (Brasil, 1965), desmatamentos ilegais e invasão de áreas de preservação permanente, entre outras infrações contra a flora, eram considerados contravenções; contudo, hoje, os desmatamentos não autorizados são crime. Esse é um fato relevante, ao qual a atividade de mineração de areia terá de se adequar.

A legislação prevê a eventual supressão de vegetação em área de preservação permanente, que, no entanto, só poderá ser procedida mediante autorização prévia, em casos específicos. As situações especiais estão previstas no artigo $4^{\circ}$ do Código Florestal (Brasil, 1965).

A análise dos conflitos legais das mineradoras de União da Vitória não poderia deixar de abordar os aspectos positivos gerados pelos procedimentos investigatórios e de fiscalização, que visam ao cumprimento da legislação ambiental.

Há poucos anos, as jazidas eram exploradas sem preocupação com a recuperação da área; após exauridas, normalmente eram abandonadas. Hoje, apesar de todas as críticas feitas, as mineradoras estão implementando projetos de recuperação de áreas degradadas. Notam-se mudanças de procedimentos na exploração da areia em cavas, que são planejadas de forma mais racional, com a preservação, em bota espera, da camada fértil do solo para recuperação futura dos taludes das cavas. Nota-se também o resultado da adoção da exploração racional em encostas de morro, cujas frentes de lavra já exauridas são revegetadas de acordo com projetos de recuperação adequados.

As mudanças são recentes e nota-se diferença no confronto entre os primeiros levantamentos realizados em 2004 e os últimos, em agosto de 2005 (Juliano, 2005). Embora os projetos de recuperação ambiental não sejam recentes, alguns são da década de 1990, somente agora é possível notar diferenças nos procedimentos adotados. Se antes os projetos de recuperação e controle ambiental eram apresentados somente para cumprir a exigência legal, hoje é possível notar as diferenças nos procedimentos em decorrência da implantação deles. Essa postura dos mineradores mostra que a fiscalização está sendo mais efetiva.

\section{CONCLUSÕES}

1. O conhecimento da legislação é fundamental, pois as leis e resoluções ambientais são bastante específicas e ditam procedimentos que devem ser observados pelos profissionais da área técnica na execução dos projetos. Para a mineração de areia, em particular, ficou evidente que conhecer os aspectos principais da legislação específica referente à mineração não é suficiente para licenciamento e funcionamento da atividade dentro dos limites legais. A falta de conhecimentos básicos da legislação ambiental por parte de engenheiros e geólogos refletese em projetos eivados de erros conceituais graves, os quais jamais poderiam ser aprovados e não cumprem com os objetivos a que se propõem.

2. Apesar de as empresas que atuam na extração de areia em União da Vitória possuírem licenças ambientais para operação, em processo de renovação, não deveriam ter sido licenciadas, uma vez que claramente, e há muito tempo, estão em situação ilegal quanto ao licenciamento mineral e ambiental.

3. Constatou-se, no decorrer da pesquisa, que o acompanhamento pelos órgãos ambientais da execução dos planos de recuperação das áreas de solos degradados começou a mostrar resultados a partir da atuação do Ministério Público Estadual. Esse fato demonstra que somente a aplicação de sanções legais tem o poder de modificar procedimentos extremamente prejudiciais ao meio ambiente, mas que são hábitos arraigados da atividade extrativista.

4. Além dos aspectos mencionados, será imprescindível equacionar uma solução para a questão da invasão das áreas de preservação permanente, que é crime ambiental praticado rotineiramente na região.

5. Finalmente, deve-se salientar que este trabalho está longe de esgotar a questão da extração de areia em União da Vitória; ao contrário, o que se pode concluir é que há muitos aspectos que devem ser estudados, pois dispõe-se na verdade de poucos dados da região.

\section{RECOMENDAÇÕES}

É preciso, sem dúvida, conhecer com maior rigor técnico todos os impactos da extração de areia na região; para isso, recomendam-se os seguintes procedimentos:

1. Monitoramento do leito do rio Iguaçu. Não há uma única informação com relação aos impactos da extração de areia no leito do rio. Muitas vezes um único porto de areia é responsável pela dragagem em uma extensa área do rio - isso é possível pela associação de várias licenças do DNPM, e não há controle algum quanto aos procedimentos da dragagem no leito. $\mathrm{O}$ 
monitoramento implica, é claro, uma periodicidade cujos procedimentos e objetivos deverão ser discutidos oportunamente; no entanto, para análise dos impactos ambientais da mineração no leito do rio, é imprescindível a realização de um levantamento ecobatimétrico, com conseqüente realização de mapeamento de fundo do rio, de preferência com geração de modelo digital do terreno, o que tornará possível a simulação da dinâmica de deposição e extração de areia, bem como definição dos possíveis volumes críticos, que podem implicar diminuição dos impactos (zoneamento para exploração).

2. Sugere-se que seja realizado um levantamento aerofotogramétrico do trecho definido pelos pontos de maior concentração de jazidas, que, por exemplo, tenha como produto final ortofotocartas ou restituição digital, para que seja possível avaliar o real impacto da extração de areia na várzea do rio Iguaçu, com especial atenção às áreas de preservação permanente.

3. A realização de um cadastro multifinalitário da atividade minerária na região estudada. Não se pode efetuar a análise dos impactos de uma atividade de extração mineral na região sem ao menos quantificar essa atividade, além de compará-la com outros usos do solo, atividades industriais, econômicas e agrícolas.

\section{AGRADECIMENTOS}

Os autores desejam externar seus agradecimentos ao Programa de Pós-Graduação em Agronomia: Ciência do Solo da Universidade Federal do Paraná e à Promotoria Pública do Estado do Paraná.

\section{LITERATURA CITADA}

AREIA E BRITA - Parque Metropolitano do Iguaçu: Mineração de areia no combate a enchentes. In: Periódico Areia e Brita. São Paulo, Abril/Junho, 1998. p.12-17. (ANEPAC, 5)

BRASIL. Lei $\mathrm{n}^{\circ}$ 4.771, de 15 de setembro de 1965, Institui o Novo Código Florestal Brasileiro. Lex: Coletânea de Legislação de Direito Ambiental, Revista dos Tribunais, São Paulo, 2004

BRASIL. Leis e Decretos etc. Lei $\mathrm{N}^{\circ} 7.804$, de 18 de julho de 1989, Altera a Lei ${ }^{\circ} 6.938$ de 31 de agosto de 1981, que dispõe sobre a Política Nacional do Meio Ambiente, seus fins e mecanismos de formulação e aplicação a Lei $\mathrm{n}^{\circ}$ 7.735 , de 22 de fevereiro de 1989 , a Lei $\mathrm{n}^{\circ} 6.803$, de 2 de julho de 1980, a Lei $n^{\circ} 6.902$, de 21 de abril de 1981,e dá outras providências. Disponível em: http:// www.planalto.gov.br. Acesso em 24/09/2005

EIA-RIMA, Médio Iguaçu. Curitiba, Júris Ambientis, 2003.

FABIANOVICZ, R. Conflitos entre a extração de areia e a expansão urbana na região da grande Curitiba.Campinas, Universidade Estadual de Campinas, 1998. 104p. (Tese de Mestrado)

JULIANO, K.A. A perícia no direito ambiental, com ênfase na degradação do solo por mineração. Curitiba, Universidade Federal do Paraná, 2005. 108p. (Tese de Mestrado)

MAGALHÃES, F.M. O aproveitamento de areia na região do alto curso do Iguaçu/Pr: Aspectos geológicos, econômicos e ambientais. Curitiba, Universidade Federal do Paraná 2002. 148p. (Tese de Mestrado)

MINEROPAR. Minerais do Paraná SA. Diagnóstico preliminar dos impactos ambientais da mineração no Paraná. Curitiba, 2001. 207p. 